\title{
The Impact of the Storage Platforms for Household Waste Bins on the Environment Depending on Their Emplacement
}

\author{
Cristina GAȘPAR ${ }^{1 *}$, Ioan ȚIBRU ${ }^{2}$ \\ ${ }^{1,2}$ Department of Animal Productions and Veterinary Public Health, Faculty of Veterinary Medicine, \\ Banat's University of Agricultural Sciences and Veterinary Medicine „King Michael I of Romania”, \\ Timișoara \\ *corresponding author: gasparcristina99@yahoo.com \\ Bulletin UASVM Veterinary Medicine 73(2) / 2016, \\ Print ISSN 1843-5270; Electronic ISSN 1843-5378 \\ DOI:10.15835/buasvmcn-vm: 12123
}

\begin{abstract}
The large amount of stored waste is still a big concern for Romania and according to the legislative provisions, until $16^{\text {th }}$ of July 2016, it has to be reduced at 35\% from the total amount of waste stored in 1995 (2). Attempting this goal depends on the extent to which the population perceives the need of selective collection, recycling and residue minimization and on the way in which the local authorities facilitates the proper conduct of this process and ensures compliance with the hygiene and public health standards in relation to the location of household waste pre-collection containers.

The aim of this paper was to verify if the previsions contained in the Order no. 119/2014, for the aproval of Hygiene and public health standards regarding the population's living environment, are complied with.

In this regard, there were conceived questionnaires concerning the emplacement of storage platforms for containers used for selective collection of household waste, containing the requirements stipulated in Chapter 1 Hygiene standards regarding the housing areas, article 4, point a) (1).

It has been found that in the living areas taken into study, the requirements stipulated in Order no. 119/2014, for the aproval of Hygiene and public health standards regarding the population's living environment, in Chapter 1 - Hygiene standards regarding the housing areas, article 4, point a), are not fully respected.
\end{abstract}

Keywords: domestic pollution

\section{INTRODUCTION}

According to to the legislative provisions regarding the regime of stored waste (2), until $16^{\text {th }}$ of July 2016, Romania should reduce the amount of stored waste at $35 \%$ from the total amount of waste generated in 1995 (2). For this purpose, there were drafted both at national and at regional, county and local level, waste management plans. Because the reduction of the amount of stored waste involves primarily the public awareness regarding minimising household waste production and the need of selective collection in order to recycle, the local authorities have the obligation to provide an efficient secondary pre-collection system (1) by which to ensure the accomplishment of these targets, but which is also in agreement with the provisions of Order no. 119/2014, for the aproval of Hygiene and public health standards regarding the population's living environment, in relation to the emplacement of the household waste precollection bins.

\section{AIMS AND OBJECTIVES}

The aim of this paper was to verify the implementation of the previsions of Order no. $119 / 2014$, for the aproval of Hygiene and public health standards regarding the population's living environment, in relation to the emplacement of 
Tab. 1. The requirements regarding the storage platforms for the selective collection of household waste

Questionnaire no.

Street

, no.

\begin{tabular}{ccc}
\hline & & YES \\
\hline 1. & $\begin{array}{c}\text { Are the bins located at least at } 10 \\
\text { m from the nearest window? }\end{array}$ \\
\hline 2. & Are the bins fenced? & NO \\
\hline 3. & Are the bins impermeable? \\
4. & $\begin{array}{l}\text { The platform for storing the bins is } \\
\text { provided with slope and water trap } \\
\text { connected to the sewerage system? }\end{array}$ \\
\hline 5. & $\begin{array}{c}\text { The platform is provided } \\
\text { with a washing sistem? }\end{array}$ \\
\hline
\end{tabular}

the household waste secondary pre-collection bins, in different areas of Timișoara.

\section{MATERIALS AND METHODS}

The first step in verifying if these requirements are met, was to conceive a questionnaire (table 1) regarding the emplacement of the platforms for temporary storage of household waste, containing the requirements laid down in Chapter 1 - Hygiene standards regarding the housing areas, article 4, point a) (1).

There were subjected to observation 100 platforms serving blocks of flats, from different areas of Timișoara and according to the questionnaire, there has been verified the compliance with the 5 requirements imposed by the Order no. 119/2014.

The distance between the bins and the nearest window was measured with a multifunctional ultrasonic detector with a measuring capacity ranging from 0.6 to 16 meters.

\section{RESULTS AND DISCUSSION}

After analyzing the observations and the measurements made, it was found that:

Only in 43 platforms out of 100 , it was respected the minimal emplacement distance (10 $\mathrm{m})$.

Only 16 platforms, each serving more than one block of flats, were concreted and fenced. In fact, in the case of the other 84 places for depositing the bins that haven't met this requirement, we could not say that an actual platform exists and we found that the bins were placed directly on the sidewalk, on the green area between the sidewalk and street or in close proximity to the access in the building.

None of the 100 platforms had a slope and water trap connected to the sewerage system or a washing sistem.

Because the bins are made from plastic material, we considered impermeable those which were undamaged.

Failure to meet these requirements is probably due to the fact that the legislative act governing them (1) entered into force recently, in 2014, and the blocks of flats taken into account were built long time ago. The 16 concreted and fenced platforms serve also old housing blocks.

\section{CONCLUSIONS}

It has been found that, in the case of all the platforms taken into account, only the requirement regarding the impermeability of the bins has been respected.

The minimal emplacement distance of the bins is compliant in just 43 cases and only 16 out of 100 platforms are fenced.

\section{REFERENCES}

1. ***, Order of Health Minister no. 119/2014, for the aproval of Hygiene and public health standards regarding the population's living environment.

2. ***, Government decision no. 349/2005, regarding the storage of wastes. 